\title{
MEMÓRIAS DE JÚLIO FRANK
}

\author{
Antonio Augusto Machado de Campos Neto \\ Chefe do Serviço Técnico de Imprensa da Faculdade \\ de Direito da Universidade de São Paulo.
}

\begin{abstract}
Resumo:
Ao lado do jornalista Líbero Badaró, Júlio Frank é uma das personalidades mais amadas do espírito liberal acadêmico da Faculdade de Direito do Largo de São Francisco. Poliglota e filósofo, lecionou no Curso Anexo, fundou a Bucha, introduziu a Filosofia alemã no País e deixou um rastro de mistério que envolve, inclusive, seu túmulo, situado no pátio interno da Academia.
\end{abstract}

\begin{abstract}
:
Next to the journalist Líbero Badaró, Júlio Frank is one of the most lovely personalities of the academic liberal spirit. Polyglot phylosopher, he teached in Anex Curse founded the called Bucha, introducted the German Physlosophy in your country and a new wave of mistery that involves his cemetery, situated in the intern patio of the Academie.
\end{abstract}

Unitermos: Júlio Frank; Biografia; Curso Anexo; Bucha.

\section{Introdução.}

Instalados em 11 de agosto de 1827 os cursos jurídicos em São Paulo e Olinda (depois Recife), o ministro do Império, Fernandes Pinheiro, apresenta a D. Pedro I os nomes do tenente-general José Arouche de Toledo Rendon, paulistano de 71 anos de idade, doutor em leis e em armas, e do professor José Maria de Avelar Brotero para, respectivamente, diretor e lente do primeiro ano dos cursos da Faculdade de Direito de São Paulo. Os nomes foram contemplados pelo imperador.

E eles foram os geniais precursores de um extraordinário elenco de diretores e professores que passaram pela Academia do Largo de São Francisco, iniciado no século retrasado. Na linha de sequiência de diretores, o segundo foi o conselheiro Dr. Carlos Carneiro de Campos (1833-1835). Natural da Bahia, o terceiro Visconde de Caravellas, nasceu em $1^{\circ}$ de novembro de 1805 e serviu como cadete no batalhão de $\mathrm{D}$. Pedro I. Atualmente, 2003, passaram pela Academia 38 diretores e centenas de professores. 
Por decreto de 24 de dezembro de 1833, foi nomeado Carlos Carneiro de Campos diretor efetivo, tomando posse a 27 do mesmo mês, exercendo o cargo até 05 de novembro de 1835. Em intervalos de tempo entre ser o inspetor geral da Fazenda e diretor da Faculdade, renunciou ao primeiro e, em 13 de janeiro de 1834, volta a ocupar, de novo, a Diretoria interina. O espaço do período foi ocupado pelo padre Maria, da Ordem Franciscana.

Cumpre salientar que a Lei de 11 de agosto criou também um curso preparatório intitulado Curso Anexo. Sua vigência se estendeu até 1896, quando pela Lei Federal n. 429, de 10 de dezembro daquele ano, em seu artigo segundo, parágrafo terceiro, foi extinto.

Em 15 de fevereiro de 1834, Carlos de Campos comunica ao ministro do Império, Antonio Pinto Chichorro da Gama, a efetivação da abertura de concurso para as cadeiras de Inglês, História e Geografia para o Curso Anexo, além de um substituto para a cadeira de Filosofia, cuja criação já havia sido aprovada pelo imperador no ano anterior.

É interessante lembrar que o ex-catedrático de Economia Política, lecionada no quinto ano, ex-deputado e ex-senador por São Paulo, Carlos de Campos, também serviu, interinamente, a função de secretário da Faculdade no período de 17 de fevereiro de 1832 a 19 de agosto de 1833, antes de sua posse como diretor, em 27 de dezembro de 1833 .

À cadeira de Filosofia, segundo relatos das atas da Secretaria da Faculdade, "apareceu um opositor a esta última que vai ser examinado, segundo os estatutos, e um moço, natural da Saxônia, que tem estado a ensinar as primeiras letras em una das Vilas desta Província, e que se propõe a concorrer às cadeiras de Geografia e de História, oferecendo-se a ensiná-las conjuntamente na cadeira de Inglês, enquanto não se preencher a vaga"

O opositor mencionado para a cadeira de Filosofia era Joaquim Inácio Ramalho que, examinado, foi aprovado e nomeado substituto do Curso Anexo à Faculdade de Direito por Ato de 9 de julho de 1834, um ano antes de se bacharelar pela Academia. E em 23 de abril de 1836, Joaquim Ramalho foi nomeado professor substituto das Arcadas, ocupando a vaga deixada pelo falecimento do professor catedrático Francisco de Paula e Oliveira.

Já o moço mencionado, natural da Saxônia, é Júlio Franck ou Julius Frank ou, ainda, Júlio Frank, de 25 anos, contemplado para lecionar no intitulado Curso Anexo que, junto a Líbero Badaró, faz desses dois professores uma marca indelével à História Antiga de São Paulo. 
Independentemente da excepcional competência profissional, já que Júlio Frank se afirmava como um dos gênios em conhecimento de História e Geografia, além das línguas inglesa, francesa e alemã, com destaque especial para as duas primeiras, uma vez ser de origem alemã, as reminiscências construídas em torno dele nos faz vibrar e apontá-lo como uma das personalidades mais comentadas e reverenciadas, além de amado e respeitado. Uma figura mística, misteriosa e inacreditavelmente humana.

Finalizando, para se ter a idéia do perfil do Curso Anexo: em parâmetro com os cursos ministrados por lentes na área do Direito, o Anexo era enquadrado como aulas menores.

Nos cursos jurídicos, lecionavam-se Direito Natural, Direito Romano, Direito Constitucional e das Gentes, como exemplo; o de aulas menores completavase a grade regida por professores especializados em línguas estrangeiras, Filosofia e Conhecimentos Gerais.

Assim as cadeiras de História, Geografia, Geometria, Filosofia, Inglês e Francês compunham, como exemplo, o currículo do Curso Anexo. Destacaram-se, naquele período do século retrasado: Diogo de Mendonça Pinto (História); cônego Fidélis Sigmaringa de Morais Cordeiro (Retórica); Manuel José Chaves (Filosofia); Mamede José Gomes da Silva (Latim) e Joaquim Antônio Pinto Júnior (Inglês e Francês).

As matérias do Curso Anexo eram consideradas como de aperfeiçoamento com instrução filosófica, de curto prazo e classificadas como estudos facílimos, porém entendiam que cursando-as poderiam viver a vida com mais facilidade, conforme matéria explanada de autoria de Spencer Vampré, em Memórias para a História da Academia de São Paulo. E acredito que estavam corretos!

II. O Mito.

Júlio Frank nasceu em 08 de dezembro de 1808, segundo registro encontrado, pesquisado e localizado na Igreja de Santa Margareth, na cidade de Gotha, Alemanha. Da gravação do seu túmulo, situado no interior do pátio menor das Arcadas, consta o ano de 1809. Cumpre salientar que Gotha, cidade natal de Júlio Frank, era um dos centros mais intelectualizados de toda a Europa, na região da Turíngia.

Descendente de familia artesã, seu pai tinha o ofício da encadernação de livros e sua mãe, auxiliando-o em horas disponíveis, dedicava-se à borda de letras dos nomes de autores e títulos dos periódicos em tecidos a serem impressos nas 
encadernações. A perfeição era de primazia, uma vez existir capas de tecidos de alto padrão como o gobelino ou, ainda, os de pele de camurça.

Júlio Frank chegou ao Brasil provavelmente em 1831 (alguns historiadores afirmam 1830), no Rio de Janeiro, instalando-se em seguida em Sorocaba, interior de São Paulo, região paulista que já abrigava alemães e italianos vindos do Exterior.

Naquela cidade trabalhou na Fábrica de Ferro Ipanema e se acomodou numa pensão em quarto alugado, cujo dono como profissão credenciada era um boticário. Após o emprego na fábrica, foi caixeiro de vendas.

Naquela pensão, com autorização do proprietário farmacêutico, dava aulas de História, Geografia, Conhecimentos Gerais e até de Inglês aos estudantes do interior de São Paulo que pretendiam vir estudar na Capital que evoluía como uma das cidades mais promissoras do País. A Faculdade de Direito colaborava para essa evolução.

Johann Julius Gottfried Ludwig Frank, nome completo, acabou vindo a São Paulo, mediante contrato de dez anos e remuneração de 600 mil réis; lecionou não-só as matérias mencionadas no Curso Anexo como, também, Latim, Italiano, Francês, Grego, Alemão e Russo, uma vez ser poliglota, incluso a língua portuguesa que dominava fluentemente, narrando-a de forma verbal e escrita como um intelectual nato. Aliás, como ele o era!

Às vezes me refiro a Júlio Frank e lembro-me do filme Sociedade dos Poetas Mortos ("Dead Poets Society"), de produção norte-americana, dirigido por Peter Weir e protagonizado por Robin Williams, interpretando o professor John Keating, arrebatando aplausos de cinéfilos do mundo inteiro. Como parâmetro, posiciono filme, protagonista, Keating e Júlio Frank, por ter sido ele o fundador da Burschenschaft Paulistana, a Bucha, sociedade secreta que em quase 100 anos dominou o universo acadêmico. As idéias da composição sócio-filosófica da Burschenschaft foram trazidas pelo jovem alemão dada a sua vida acadêmica passada na Universidade de Gotha.

III. A Bucha.

A finalidade primordial da sua fundação era a de proteção aos estudantes de família pobre, oferecendo-lhes apostilas gratuitas, livros e até recursos financeiros para a sua manutenção, não-só do próprio estudante como às famílias de baixa renda, à qual o estudante, por ventura, pertencia. 
A Casa dos Estudantes, localizada na Avenida São João, por e, emplo, foi concebida para abrigar os alunos mais pobres e é inicialmente um projsto dos "associados" da Bucha. O mais incentivador da construção do prédio que hoje os abriga em seus três apartamentos, por andar, distribuídos nos onze andares em terreno doado pela Prefeitura Municipal, foi Cícero Augusto Vieira, presidente do Centro Acadêmico XI de Agosto no ano de 1936. A inauguração deu-se, durante a gestão de José Antonio Rogê Ferreira na presidência do XI de Agosto, em 09 de março de 1949.

A premissa maior e a mais importante era a de que toda ação se realizasse em segredo, evitando-se a humilhação aos olhos do seu benfeitor. Literalmentc Burschenschaft significa sociedade dos jovens. Bursche significa jovem e schaft, corporação, na língua alemã.

A Bucha, como sempre foi chamada pelos estudantes e professores da Academia, por seu mérito em si, não deixou de ser uma sociedade filantrópica, tendo dela participado, dentre outros, Paulo Duarte, Joaquim Celidônio Filho, José de Molina Quartim Filho, cabendo-se mencionar sobre este último: "autoridade policial assassinada em Campinas, interior de São Paulo, homem de prestígio e sabedoria, além dos exímios conhecimentos em política social" ênfase dada pelo ex-diretor da Faculdade de Direito, em 1938, professor Spencer Vampré, ex-catedrático de Direito Romano e de Filosofia do Direito em seus livros de memórias da Academia. Diógenes Ribeiro de Lima e Hugo Celidônio completam o quadro dos mais conhecidos.

A Bucha, além da filantropia, difundia no perfil daquela sociedade idéias liberais, republicanas e abolicionistas. O espírito liberal sempre predominou no seio das Arcadas e segundo o monstro sagrado do Direito e da Filosofia, Miguel Reale, " $a$ liberdade inspirou a fundação da Bucha na Faculdade de Direito"

Cumpre salientar que a sociedade de per si não tinha o propósito da Loja Maçônica, como muitos relatam; posicionou-se sempre ativa e dela saíram, por terem sido "associados", personalidades políticas como os ex-presidentes civis Affonso Penna, Prudente de Moraes, Campos Salles, Rodrigues Alves e jornalistas, juristas, literatos e historiadores como Barão do Rio Branco, Ruy Barbosa, Afonso Arinos, Júlio de Mesquita Filho, Pinheiro Machado, Bernardino de Campos, Cândido Mota, César Vergueiro, Waldemar Ferreira, Henrique Bayma, Spencer Vampré, Antonio Carlos de Abreu Sodré e Francisco Morato.

Obviamente foram homens importantes pós-Bucha, todavi; envolvidos nos anos seqüênciais daquela sociedade e, enfatiza-se, reverenciavam s:mpre o seu fundador: Júlio Frank. 
Como pinceladas de histórico final: a Burschenschaft foi criada por volta de 1815 nas principais universidades da Alemanha. Tratava-se de uma sociedade extremamente perseguida e arrasada pelo ditador Adolf Hitler, sendo totalmente extinta no período nazista. Todavia, com o término da Segunda Guerra Mundial, resplandeceu com todo o vigor nos campi das universidades alemãs.

Relembremos que da Bucha adveio a Festa da Chave, que poucos entendiam o seu significado, após a morte de Júlio Frank. Embora a sociedade secreta de cunho liberal e filantrópico tenha ficado para traz e o corpo do seu fundador tenha sido enterrado nos pátios das Arcadas, o espírito da Bucha permaneceu por muito tempo na Academia.

A Festa da Chave serve de parâmetro; marcava a passagem da chefia da Bucha das mãos de um formando para as de um aluno quartanista. A chave simbólica era enorme, com detalhes esculpidos imitando uma tocha, símbolo da iluminação de letrados. Em 1968, ela foi identificada nos arquivos de aço velhos da secretaria do Centro Acadêmico XI de Agosto, ano da tomada da Faculdade pelos estudantes daquele período que reivindicavam a reforma do ensino. Após invasão da Polícia no Centro Acadêmico, a chave nunca mais foi vista.

A Festa da Chave é fato sempre relembrado pela professora titular Ada Pellegrini Grinover, da Faculdade de Direito da Universidade de São Paulo. O Museu da Faculdade de Direito que pertence à área do Serviço Técnico de Imprensa possui um molho de chaves usado no cerimonial da Festa da Chave, inserido entre os demais objetos de relíquia na mesa de número $0 \mathrm{I}$, que acompanha o roteiro intitulado Momento $/$. integrando a história da Academia. Neste mesmo roteiro, Momento l, mesa 0I, do Museu da Faculdade há uma cópia do registro de estrangeiro de Júlio Frank, de 1831, cujo original está arquivado na Seção de Documentação Histórica do Arquivo Nacional do Rio de Janeiro.

Assim como a Bucha criada na Faculdade de Direito, também existiam concomitente, dada a expansão espiritual, a Bucha da Faculdade de Medicina, intitulada Jungendschaft e a da Escola Politécnica, ambas de São Paulo, sendo esta última intitulada Landsmannschaft.

O único opositor da Bucha, no País, e conseqüentemente de Júlio Frank, foi o pesquisador e historiador Gustavo Barroso, autor de História Secreta do Brasil. O historiador, em pauta, em suas publicações elogiava o nazismo e arrasava a Bucha, cujo propósito maior era o de atingir o jovem alemão.

Gustavo Barroso ainda assevera ter sido Júlio Frank o assassino do escritor Augusto von Kotzebüe, que se comenta logo a seguir. 
IV. A personalidade.

O jovem alemão, em uma das atividades pessoais de cidadania, naturalizou-se brasileiro. Ressalto que, por ser estrangeiro, não pôde ser o titular da cadeira de História e Geografia. Apenas conseguiu ser contemplado com um contrato, assinado pelo presidente da Província, Rafael Tobias de Aguiar, de dez anos que, inclusive, também não pôde completá-lo, uma vez ter falecido em 19 de junho de 1841, sendo substituído por um de seus melhores alunos e amigo: Antônio Joaquim Ribas.

Antônio Ribas por aprender a língua alemã com Júlio Frank se tornou o primeiro jurista do País a se fundamentar em fontes do Direito alemão, segundo o filósofo e jurista Miguel Reale.

Júlio Frank morreu de forte gripe mesclada à pneumonia aos 32 anos de idade incompletos.

Ausente o seu nome em capa ou interior, miolo do livro, o que obviamente iria contrariar os pais encadernadores, deixou publicado História Universal, de 1839, em dois volumes, encontrados no Departamento de Obras Raras, do Serviço de Biblioteca e Documentação, SBD, da Faculdade de Direito do Largo de São Francisco.

Os livros são em língua portuguesa e consta da Introdução que Júlio Frank não tinha nenhuma pretensão de inovação a não ser, exclusivamente, a de realizar uma obra didática para os ensinos do Curso Anexo.

Na Alemanha há vários artigos publicados por Júlio Frank, armazenados e encontradiços em bibliotecas da capital alemã, Berlim.

Inegavelmente essa figura de mistério que o acompanha desde a sua morte, de personalidade discreta, repleta de segredos, idealista, bondade extremada e filantrópica, de belezas interna e externa continua ainda a ser reverenciada, venerada e cogitada como o mais devotado amigo dos estudantes da História da Academia do século XIX. Assim como foi no século XX o professor Spencer Vampré que conservava um jardim em pedras e cultivava rosas, em sua espiritualidade particular, nos pátios das Arcadas, como dizia o ex-catedrático da Academia e Professor Emérito pela Reitoria da Universidade de São Paulo, Goffredo da Silva Telles Júnior.

Desde a entrada de Júlio Frank no nosso País sempre existiram segredos quanto à sua vida e nada é dito corretamente a seu respeito, incluso antes da sua chegada ao porto do Rio de Janeiro. 
Existe versão de que até de nome trocara, talvez por desgosto pessoal. Escusas também são as histórias de sua saída da região da Baviera: por fugir de dívidas contraídas e problemas políticos.

Há relatos de que tivera assassinado o escritor Augusto von Kotzebüe, em março de 1819, conforme comentado anteriormente, por ser Kotzebüe considerado inimigo da Alemanha e espião do Czarismo russo. A hipótese foi descartada, uma vez pesquisadores e historiadores como Brasil Bandecchi confirmarem que, durante a morte do escritor, Júlio Frank tinha apenas oito anos de idade.

Em sua chegada ao Rio de Janeiro, de navio intitulado Carlota I, o comandante-do-navio prestou queixa do jovem alemão, acarretando-lhe alguns dias de prisão na Fortaleza do Laje. A queixa, presume-se, foi por ter ele embarcado clandestinamente.

E foi assim o jovem Júlio Frank que teve acentuada influência nos também jovens estudantes brasileiros: organizador e fundador de uma sociedade secreta, de rosto afilado, fronte alta, cabelos enrolados em cachos loiros, lábios carnudos e perfeitos; olhos brilhantemente azuis e estatura elevada, conforme descrição, de 1883, do pesquisador e viajante Koseritz, seu conterrâneo, quando se referiu a ele ao olhar o quadro a óleo que se encontrava na Sala de Leitura da Biblioteca. Segundo Koseritz, conquistava a quem se lhe aproximasse.

\section{O Túmulo.}

Nos tempos atuais, em visitas monitoradas à Faculdade de Direito inserese o local de seu túmulo que, até hoje, fica cm frente à Sala em que ele lecionava. É construído por plataforma quadrilátera que dá acesso a três degraus, em cujo cume encontra-se um obelisco de cerca de quatro metros.

O túmulo é devidamente cercado por gradil de ferro com lanças nos ângulos a quatro pilastras que são adornadas, internamente, por quatro corujas, o símbolo da Sabedoria e quatro tochas, externamente, simbolizando a Iluminação das Letras.

Em dias de chuva e até de tempestade, nota-se que as simbólicas corujas não são molhadas e permanecem impecavelmente secas. A história das corujas ou mochos virou lenda e é contada e repassada a todas as turmas das Arcadas!

Cumpre salientar que o mausoléu foi realizado em 1841 graças à iniciativa de acadêmicos que pertenceram à Burschenschaft Paulistana, os quais, inclusive, mandaram pintar o retrato a óleo de Júlio Frank, quadro que se encontrava na Sala de Leitura da Biblioteca, localizada no primeiro andar do prédio histórico. 
Spencer Vampré indicou a localização referida do quadro no ano de 1924 em seu livro intitulado Memórias da Faculdade de Direito. Nunca mais se soube onde o quadro se encontrava. Assustadoramente sumiu da Academia.

O motivo da inumação no pátio menor das Arcadas foi o de Júlio Frank ser adepto do protestantismo e também porque o bispo de São Paulo, da época, não consentiu que ele fosse enterrado na Igreja. O sepultamento em igrejas, único local conhecido às pessoas notáveis, só se realizava nos templos católicos.

E é esse mesmo espaço físico que serve de reunião a todos os estudantes e interessados em participar das récitas realizadas à meia-noite de toda a última sextafeira do meses pares, promovidas pela Academia de Letras do Centro Acadêmico XI de Agosto. Velas acesas, vinho quente no inverno servem de complemento ao visual noturno que se torna elegante e agradável, dada a espiritualidade do local. Poesias, poemas, contos são declamados e contados por alunos da Escola e convidados, ao som de instrumentos de corda. Era imperdível. Atualmente o lugar tem-se apresentado fechado e as visitas têm de ser monitoradas.

O professor de tipografia Antônio Alexandrino dos Passos Ourique, formado pelo Gabinete Topográfico de São Paulo, instituto criado por lei provincial, na ocasião da morte de Júlio Frank, consternado, é o autor dos versos gravados em Tradiçóes e Reminiscências, v. 9, p.18, de autoria de Almeida Nogueira:

Oh! La Caille, La Borda, Wahl D'Auville,

Las Casas, Kant, Schiller e Buffon,

Herodoto, De Lille;

Tu também Fénelon;

Segunda vez ao túmulo baixastes;

Morreu aquele a quem saber legastes!

Ilustre Blumenback, o teu amigo,

O sábio Júlio, o Júlio sem igual,

Existe no jazigo;

E da ciência a estrada, eis sem fanal!

Morreu desconhecido; e do bonzo a fanática virtude

Não quis, compadecida,

Dar-lhe asilo sagrado ao ataúde. 
Mas, que sepulcro existe mais ditoso

Que nossos corações?

Que lugar mais sagrado, mais honroso,

Que cantos, que aspersões,

Equivalem ao pranto, aos ais, ao luto!

E negaram-lhe os homens tal tributo!

Oh! Não! Que infâmia era,

Nem os humanos têm alma tão fera!

Oh!, tu, Júlio feliz, benquisto Júlio,

Que desfrutas na plácida mansão,

De seres virtuoso

Divinal compensão,

Acolhe os sentimentos de amizade,

De respeito e de amor, com que teu nome

À sã posteridade

Há de ser transmitido com renome!

E em uma das laterais do pedestal de quatro metros há os seguintes dizeres:

Hic jacet Julius Franck

In hac Paulopol. Academ. Publ. Prof.

Nathus Gothae. Ann.MDCCCIX

Obiit XIX Junii Ann. MDCCCXLI

Aetate suae XXXII

Sit ei terra levis.

VI. Conclusão.

Na Revista O Onze de Agosto, de julho de 2001, há um trabalho redatorial, no qual se expressa com muita sensibilidade:

"Ele se colocou na sociedade paulistana em lugar

Tão destacado que jamais o seu nome poderá

Ser olvidado por aqueles que vêm à Faculdade aprender a Ciência do Direito" 
O amor à Pátria, para o também monstro sagrado do Direito è da Filosofia, Goffredo da Silva Telles Júnior, professor emérito, aposentado e titular de Introdução à Ciência do Direito desta Faculdade de Direito, significa "simplesmente o amor ao povo, a apaixonada defesa de sua dignidade, dos patrimônios material e espiritual que por direito lhe pertence"

E Júlio Frank, naturalizado, cumpriu a assertiva do grande mestre de Direito. Foi o introdutor da Filosofia alemã no Brasil. Adotou o País como sua Pátria amada. Foi o introdutor da primeira sociedade que buscou a proteção dos nossos estudantes brasileiros.

Que figura marcante e inesquecível!!!

São Paulo, fevereiro de 2003.

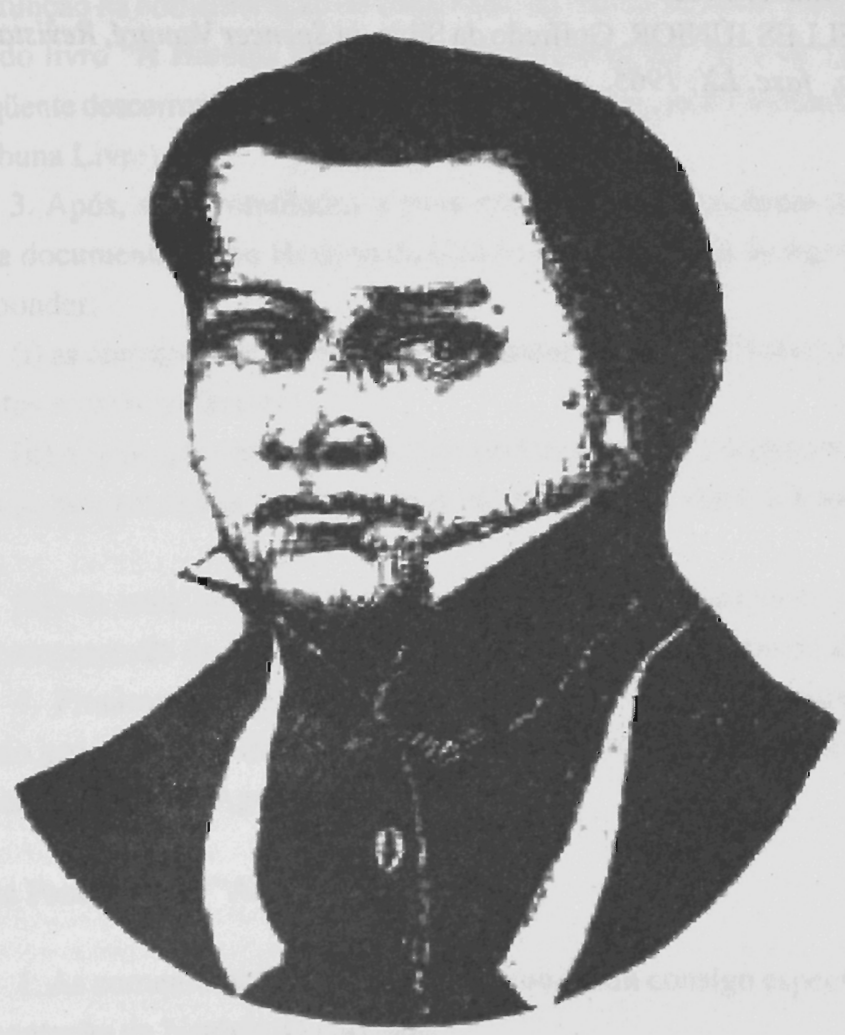

Júlio Frank 
VII. Bibliografia.

VAMPRÉ, Spencer, Memórias para a História da Academia de São Paulo, v. I, segunda edição, pp. 165-169 e 260, 1977;

REALE, Miguel, Memórias, v. I, pp. 55-56, 1987;

MARTINS, Ana Luísa; / BARBUY, Heloisa, Arcadas, História da Faculdade de Direito do Largo de São Francisco, pp 48 e ss., 1999;

BARROSO, Gustavo; História Secreta do Brasil, Parte II, pp. 32-35, 1937;

NASCIMENTO FRANCO, J. Ainda a, Sombra de Julio Frank... pp. 1-16,1998;

NOGUEIRA, Almeida, Tradições e Reminiscências, v. 9, pp. 18-19;1979;

CAMPOS NETO, A.A.M. / BORGES MENDONÇA, Andrey; A Fundação dos Cursos Jurídicos no Brasil, in Revista da Faculdade de Direito da Universidade de São Paulo, v. 95, p. 200, 2000.

MARCONDES MACHADO JR., Armando, Centro Acadêmico XI de Agosto, segundo volume, 2001.

TELLES JÚNIOR, Goffredo da Silva, in Spencer Vampré, Revista da Faculdade de Direito, fasc. LX, 1965. 